Hal: $23-32$

\title{
TEKNOLOGI PENANGKAPAN POCONG-POCONG UNTUK GURITA DI KECAMATAN KABAENA BARAT SULAWESI TENGGARA
}

\author{
Pocong-pocong, a Fishing Gear Technology of Octopus in West Kabaena District, \\ Southeast Sulawesi \\ Oleh: \\ Rita L. Bubun ${ }^{*}$, Amir Mahmud ${ }^{2}$ \\ 1Program Studi Pemanfaatan Sumberdaya Perikanan, Fakultas Perikanan dan Ilmu Kelautan, Universitas \\ Muhammadiyah Kendari.rl.bubun@gmail.com \\ 2 Program Studi Pemanfaatan Sumberdaya Perikanan, Fakultas Perikanan dan Ilmu Kelautan, Universitas \\ Muhammadiyah Kendari.alghiamir@gmail.com \\ *Korespondensi: rl.bubun@gmail.com
}

Diterima: 07 April 2017; Disetujui: 17 April 2019

\begin{abstract}
Pocong-pocong is one type of handline fishing gear used to catch octopus in West Kabaena District, Southeast Sulawesi. The research objectives was to examine the fishing gear technology of pocong-pocong related to its construction, the method of fishing, and the effectiveness of octopus capture in West Kabaena District of Southeast Sulawesi. The research method used is a survey method by collecting data based on the results of observations at the study site. Data analyze are using qualitative and quantitative descriptive. The results showed that the technical aspects of pocong-pocong fishing gear still used a simple construction with the main components of this fishing gear were hooks and a attractor that resembles an octopus. The catching methods of pocong-pocong fishing gear by pulling back and forth. The effectiveness of temporal octopus catches in West Kabaena District is based on the moon phase that is in the third month phase of $48 \%$, based on season which is in the west season by $90 \%$, based on the time of arrest can be done at noon at 06.00-12.00 Central Indonesian Time.
\end{abstract}

Keywords: effectiveness, octopus, pocong- pocong

\begin{abstract}
ABSTRAK
Pocong-pocong merupakan salah satu jenis alat tangkap hand line yang digunakan untuk menangkap gurita di Kecamatan Kabaena Barat. Tujuan penelitian yaitu mengkaji teknologi penangkapan gurita dengan menggunakan alat tangkap pocong-pocong, terkait aspek teknis dan efektivitas secara temporal di Kecamatan Kabaena Barat Sulawesi Tenggara. Metode penelitian yang digunakan adalah metode survei dengan pengumpulan data berdasarkan hasil observasi di lokasi penelitian. Analisis data yaitu analisis deskriptif kualitatif dan deskriptif kuantitatif. Hasil penelitian menunjukkan aspek teknis alat tangkap pocong-pocong memiliki kontruksi sederhana dengan komponen utama dari alat tangkap yaitu mata pancing dan atraktor yang berumbai-rumbai menyerupai gurita. Metode penangkapan alat tangkap pocong-pocong dengan cara ditarik-ulur. Efektivitas penangkapan gurita secara temporal di Kecamatan Kabaena barat yaitu berdasarkan fase bulan yaitu pada fase bulan III sebesar $48 \%$; berdasarkan musim yaitu pada musim barat sebesar $90 \%$; berdasarkan waktu penangkapan dapat dilakukan pada siang hari pada pukul 06:00 WITA-12;00 WITA.
\end{abstract}

Kata kunci: efektivitas, gurita, pocong-pocong 


\section{PENDAHULUAN}

Gurita merupakan salah satu sumberdaya perikanan yang menjadi primadona ekspor di Indonesia. Pemanfaatan gurita di berbagai wilayah di Indonesia dilakukan dengan berbagai macam alat tangkap. Gurita sebagai potensi perikanan binatang lunak non ikan di Sulawesi Tenggara, pada awalnya hanya menjadi hasil tangkapan sampingan bagi nelayan yang menangkap ikan demersal. Namun berdasarkan data statistik Dinas Perikanan dan Kelautan Propinsi Sulawesi Tenggara tahun 2013, menunjukkan nilai produksi ekspor gurita sebagai produk perikanan menduduki posisi kedua setelah cakalang. Hal ini menjadikan produksi gurita sebagai produk unggulan daerah saat ini. Produksi gurita telah memberikan masukan anggaran untuk Sulawesi Tenggara pada skala ekspor produk perikanan binatang lunak.

Pemanfaatan sumberdaya gurita di beberapa tempat dengan beragam alat tangkap dan umpan, diantaranya yaitu masyarakat nelayan di Kepulauan Karimunjawa melakukan penangkapan gurita menggunakan alat tangkap pancing gurita yang disebut dengan jigger yang dilengkapi dengan umpan tiruan menyerupai kepiting (Nurdiansyah et al. 2015); nelayan di Perairan Baron Gunung Kidul menggunakan pancing ulur dan jigger dengan umpan tiruan menyerupai kepiting dan udang (Farikha et al. 2014); nelayan di perairan Desa Sei Nagalawan Sumatera Utara menggunakan alat tangkap bubu untuk menangkap gurita (Safari et al. 2012); Bubu lipat (collapsible pot) telah dioperasikan secara komersial oleh nelayan di Jepang untuk menangkap gurita (Archdale et al. 2003 diacu dalam Zulkarnain et al. 2011); Nelayan di Kawasan Lhokseudu Kecamatan Leupung Kabupaten Aceh Besar masih menggunakan tombak (Yuliani et al. 2016). Penangkapan gurita di Sulawesi Tenggara seperti di Kabupaten Wakatobi dan Kabupaten Bombana umumnya menggunakan alat tangkap tradisional yang dikenal dengan alat tangkap pocong-pocong.

Kecamatan Kabaena Barat merupakan salah satu wilayah administratif dari Kabupaten Bombana. Daerah ini termasuk daerah pesisir pantai yang berhadapan langsung dengan Laut Banda dan Teluk Bone. Penelitian ini berbasis di Desa Baliara dengan mata pencaharian penduduk berasal dari sumberdaya perikanan. Komposisi mata pencarian penduduk Kecamatan Kabaena Barat mempunyai mata pencarian sebagai nelayan lebih dominan sebesar $58 \%$ dibandingkan mata pencaharian penduduk lainnya. Jumlah nelayan yang mengoperasikan alat tangkap pocong-pocong sebanyak 65 unit atau $52 \%$ dari $58 \%$ jumlah nelayan di Kecamatan Kabaena Barat (Data Kecamatan Kabaena Ba- rat 2015). Jumlah nelayan yang menggunakan alat tangkap pocong-pocong semakin meningkat. Mengingat pertumbuhan alat tangkap pocong-pocong yang terus meningkat setiap tahunnya, apabila keberadaan alat tangkap tersebut tidak dikelola dengan baik, maka dikhawatirkan alat tangkap tersebut akan mengakibatkan terjadinya overfishing untuk perikanan gurita di Kecamatan Kabena Barat.

Penggunaan pocong-pocong sebagai alat tangkap gurita tradisonal telah lama digunakan masyarakat nelayan di Kecamatan Kabena Barat. Hasil wawancara dengan nelayan gurita menyebutkan bahwa hasil tangkapan gurita menggunakan alat tangkap pocong-pocong fluktuatif setiap tahunnya. Namun hasil tangkapan gurita telah memberikan tambahan penghasilan bagi masyarakat nelayan gurita di Kecamatan Kabena Barat. Untuk menghindari terjadinya overfishing pada perikanan gurita akibat keberadaan pocong-pocong, maka perlu dilakukan kajian awal untuk mengetahui konstruksi dari alat tangkap tersebut serta efektivitas alat tangkap tersebut untuk menangkap gurita. Berdasarkan uraian tersebut maka tujuan penelitian yaitu mendeskripsikan secara lengkap kontruksi dan menganalisis efektivitas penangkapan gurita secara temporal di Kecamatan Kabaena Barat Sulawesi Tenggara. Informasi tentang efektivitas pengoperasian pocong-pocong nantinya dapat dimanfaatkan oleh dinas perikanan setempat untuk pengaturan waktu pengoperasian alat tangkap pocong-pocong.

\section{METODE}

Penelitian dilaksanakan pada bulan Junibulan Nopember 2016. Lokasi penelitian di perairan Kecamatan Kabaena Barat Kecamatan Kabaena Barat Kabupaten Bombana. Daerah penangkapan Gurita di Kecamatan Kabaena Barat dapat dilihat pada Gambar 1.

Metode penelitian yang digunakan adalah metode survey, untuk memperoleh gambaran yang dapat mewakili pemanfaatan sumberdaya gurita di Kecamatan Kabaena Barat. Teknik pengumpulan data dengan observasi dan wawancara langsung terhadap 10 orang nelayan pancing pocong-pocong. Data yang dikumpulkan dalam penelitian ini antara lain data primer dan skunder. Data primer terdiri dari konstruksi alat tangkap pocong-pocong, metode pengoperasian alat tangkap, daerah penangkapan gurita, jenis hasil tangkapan gurita di lokasi penelitian. Data skunder terdiri dari hasil tangkapan gurita Tahun 2010-2015, jurnal terkait penelitian dan referensi pendukung penelitian ini. Data hasil tangkapan gurita Tahun 2010-2015 digunakan untuk menentukan efektivitas penangkapan 


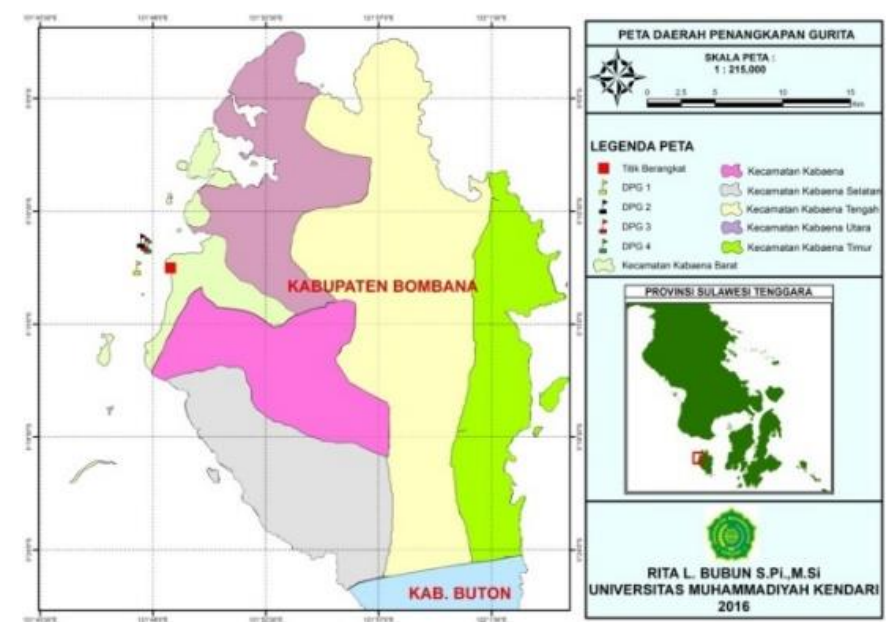

Gambar 1 Peta daerah penangkapan gurita di Kecamatan Kabaena Barat

yang terkait dengan musim penangkapan. Hasil wawancara dengan nelayan setempat menjelaskan bahwa musim penangkapan gurita di Kabaena Barat tejadi dua musim yaitu musim barat dan musim timur. Musim barat berlangsung pada bulan Januari-bulan Juni. Musim timur berlangsung pada bulan Juli-bulan Desember.

Analisis data yang digunakan yaitu analisis deskriptif kualitatif dan kuantitatif. Analisis deskriptif kualitatif digunakan untuk menggambarkan hal-hal terkait kontruksi alat tangkap pocong-pocong dan metode penangkapan gurita menggunakan pocong-pocong. Analisis deskriptif kuantitatif untuk menentukan efektivitas penangkapan gurita secara temporal di Kecamatan KabaenaBarat Sulawesi Tenggara.

Simbolon et al. (2011) menjelaskan bahwa efektivitas suatu alat tangkap adalah ratio persentase alat tangkap dengan total tangkapan dari semua alat tangkap. Informasi tersebut dapat digunakan sebagai pendekatan dalam menghitung efektivitas penggunaan pocongpocong terhadap hasil tangkapan gurita pada waktu tertentu. Efektivitas alat tangkap pocongpocong diketahui dengan membandingkan jumlah hasil tangkapan gurita pada masing-masing musim dengan total hasil tangkapan semua musim. Formula efektivitas penggunaan pocong-pocong dirumuskan sebagai berikut :

$E_{f}=\frac{\sum n_{i}}{\sum_{j=1}^{i} n_{j}} x 100 \%$

Keterangan :

$$
\begin{aligned}
& E_{f}= \text { Efektivitas penggunaan pocong- } \\
& \text { pocong; } \\
& \sum n_{i}= \text { Jumalah hasil tangkapan gurita } \\
& \text { pada waktu ke } i ; \\
& \sum_{j=1}^{i} n_{j}=\begin{array}{l}
\text { Jumlah total hasil tangkapan gurita } \\
\text { pada semua waktu }
\end{array}
\end{aligned}
$$

Kategori nilai efektivitas waktu penangkapan gurita pada alat tangkap pocong-pocong menggunakan penedekatan nilai efektivitas penangkapan menurut Baskoro et al. (2006). Nilai efektivitas penangkapan gurita yaitu: (1) jika nilai $E_{f}<50 \%$, maka waktu penggunaan pocong-pocong kurang efektif; (2) jika nilai $50 \%<E_{f}<80 \%$, maka waktu penggunaan pocong-pocong efektif; (3) jika nilai $E_{f}>80 \%$, maka waktu penggunaan pocong-pocong sangat efektif.

\section{HASIL}

\section{Konstruksi Alat Tangkap Gurita}

Alat tangkap pocong-pocong sebagai salah satu alat tangkap gurita yang digunakan oleh nelayan di Kecamatan Kabena Barat. Penyebutan nama pocong-pocong berasal dari masyarakat setempat, sebab alat tangkap ini menyerupai pocong. Hasil penelitian menunjukkan bahwa satu unit pancing pocong-pocong terdiri dari atraktor, dan mata pancing. Konstruksi pocong-pocong dapat dilihat pada Gambar 2.

Kontruksi alat tangkap secara lengkap terdiri dari bagian kepala, badan, tali atraktor, tali pancing dan mata pancing. Mata pancing terpisah dari bagian atraktor seperti terlihat pada Gambar 2. Deskripsi alat tangkap secara lengkap dapat dilihat pada Tabel 1.

Bagian Kepala yang berbentuk bola memiliki diameter $\pm 12 \mathrm{~cm}$ dan tinggi $14 \mathrm{~cm}$. Pada bagian kepala dan badan atraktor terdapat tali pengikat atraktor. Tali ini berfingsi sebagai pengikat kain atraktor agar pada saat diturunkan di dalam air, kain atraktor tidak mudah terlepas. Bagian badan terdapat jari-jari atau rumbairumbai (atraktor) dengan ukuran panjang bervariasi dari 30 sampai dengan $40 \mathrm{~cm}$. Pema- 


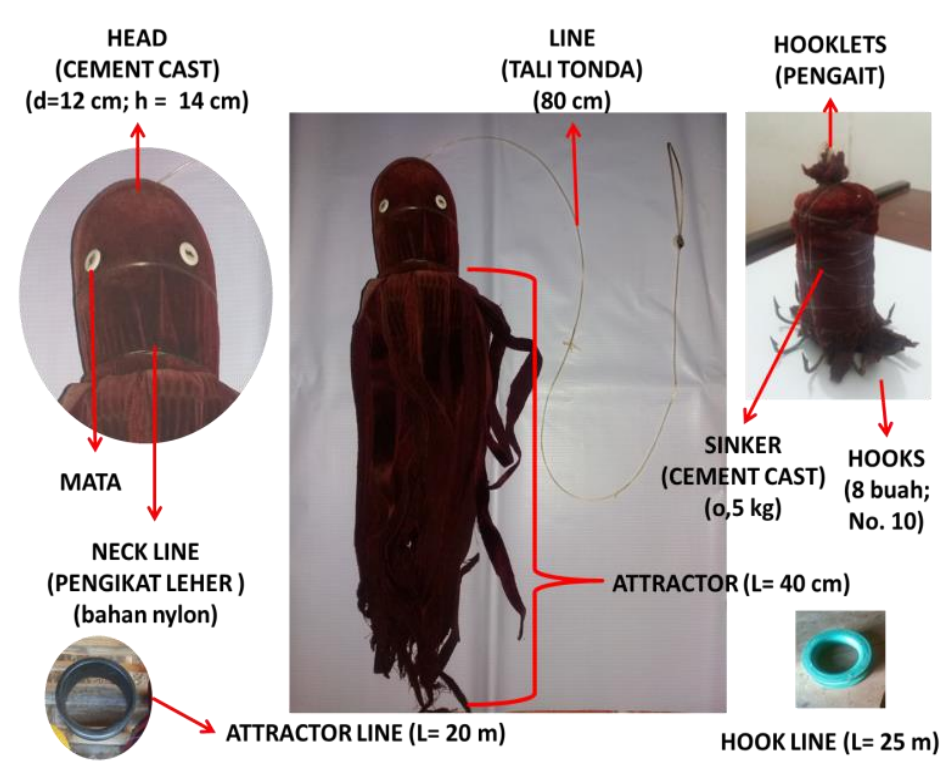

Gambar 2 Konstruksi pocong-pocong

Tabel 1 Deskripsi kontruksi alat tangkap pocong-pocong

\begin{tabular}{|c|c|c|c|}
\hline No & Item & Bahan & Ukuran \\
\hline 1 & Kepala & $\begin{array}{l}\text { Semen cor (cast } \\
\text { cement) }\end{array}$ & $\begin{array}{l}\text { Diameter }(\varnothing)=12 \mathrm{~cm} \\
\text { Tinggi }(h)=14 \mathrm{~cm} \\
\text { Berat }(w)=5 \mathrm{Kg}\end{array}$ \\
\hline 2 & Mata & Plastik & $\varnothing=0,5 \mathrm{~cm}$ \\
\hline 3 & Pengikat leher & $\begin{array}{l}\text { Nylon monofilamen } \\
\text { (PA) }\end{array}$ & $\varnothing=2 \mathrm{~mm}$ \\
\hline 4 & Atraktor & Kain warna merah & $\mathrm{L}=40 \mathrm{~cm}$ \\
\hline 5 & Tali atraktor & $\begin{array}{l}\text { Nylon monofilamen } \\
\text { (PA) }\end{array}$ & $\begin{array}{l}\varnothing=2 \mathrm{~mm} \\
\mathrm{~L}=20 \mathrm{~m}\end{array}$ \\
\hline 6 & Pemberat (sinker) & $\begin{array}{l}\text { Semen cor (cast } \\
\text { cement) }\end{array}$ & $\begin{array}{l}\varnothing=4 \mathrm{~cm} \\
\mathrm{~h}=10 \mathrm{~cm} \\
\mathrm{w}=0,5 \mathrm{~kg}\end{array}$ \\
\hline 7 & Mata pancing (hook) & Stainless steel & $\begin{array}{l}\text { Jumlah }=8 \text { buah } \\
\text { Nomor } 10\end{array}$ \\
\hline 8 & Tali pancing (hook line) & $\begin{array}{l}\text { Nylon monofilamen } \\
\text { (PA) }\end{array}$ & $\begin{array}{l}\varnothing=2 \mathrm{~mm} \\
\mathrm{~L}=80 \mathrm{~cm}\end{array}$ \\
\hline
\end{tabular}

sangan rumbai-rumbai pada pocong-pocong bertujuan untuk menarik perhatian gurita keluar dari sarangnya. Alat tangkap pocong-pocong dilengkapi dengan tali tonda dengan panjang 80 $\mathrm{cm}$ dan tali atraktor sepanjang $20 \mathrm{~m}$ terbuat dari bahan nylon monofilamen (PA).

Alat tangkap pocong-pocong ini berbeda dengan alat tangkap pancing lainya, sebab bagian dari pancingnya terpisah dari badan atraktor. Bagian pancing berbentuk seperti tabung yang terbuat dari bahan semen cor. Bagian ini berfungsi juga sebagai pemberat dan tempat melekatnya mata pancing. Berat bagian ini 0,5 $\mathrm{kg}$ dengan diameter $4 \mathrm{~cm}$ dan tinggi $10 \mathrm{~cm}$. Pada bagian ini melekat mata pancing nomor $10 \mathrm{se}$ banyak 8 buah. Bagian pemberat ini dilengkapi dengan tali dari bahan nylon monofilamen (PA) dan panjang $25 \mathrm{~m}$.

\section{Metode Penangkapan Alat Tangkap Pocong-pocong}

Prinsip metode penangkapan pancing pocong-pocong yang dilakukan oleh masyarakat di Kabaena Barat umumnya sama dengan penggunaan alat tangkap pancing lainnya. Metode penangkapan pocong-pocong yaitu dengan mengikatkan tali atraktor pada perahu dan atraktor diturunkan sampai pada kedalaman perairan $\pm 5 \mathrm{~m}$ dari permukaan laut. Posisi atraktor melayang di perairan. Pada saat atraktor berada di perairan, tali atraktor digerak-gerakkan (ditarik-ulur). Hal ini dilakukan untuk memancing gurita untuk keluar dari sarangnya. Pada saat gurita mulai mendekati dan menerkam atraktor, maka alat tangkap pancing diturunkan, agar bagian dari gurita dapat terkait pada mata pancing. Metode penangkapan ikan dapat dilihat pada Gambar 3. 


\section{Daerah Penangkapan Gurita}

Masyarakat nelayan gurita di Kecamatan Kabaena Barat melakukan operasi penangkapan ikan pada jarak 1,5 mil dari pesisir pantai Kecamatan Kabaena Barat sebagai fishing base. Titik koordinat daerah penangkapan gurita pada saat observasi berada pada $05^{\circ} 11^{\prime} 40,8^{\prime \prime}$ $05^{\circ} 12^{\prime} 04^{\prime \prime}$ Lintang Selatan dan 121 $47^{\prime} 23^{\prime \prime}$ $121^{\circ} 47^{\prime} 49,5^{\prime \prime}$ Bujur Timur. Suhu permukaan laut di daerah penangkapan gurita berkisar $27^{\circ} \mathrm{C}$ $28^{\circ} \mathrm{C}$ dan salinitas berkisar $35 \%$. Kedalaman perairan pada saat pasang tinggi mencapai 25 meter dan pada saat surut terendah mencapai 15 meter. Kondisi dasar perairan terdiri dari terumbu karang dan lamun dengan substrat berpasir, namun kondisi terumbu karang cenderung tidak produktif. Kondisi dasar perairan Kecamatan Kabaena Barat dapat dilihat pada Gambar 4.

\section{Efektivitas Penangkapan Gurita secara Temporal di Kecamatan Kabaena Barat}

Produksi gurita di Kecamatan Kabaena Barat secara temporal berdasarkan data insitu yang diperoleh pada saat observasi dan wawancara langsung dengan nelayan gurita. Jenis gurita yang umumnya tertangkap di perairan Kecamatan Kabaena Barat yaitu jenis Octopus cyanea. Ukuran gurita yang tertangkap rata-rata berukuran $\pm 40 \mathrm{~cm}$ dengan berat rata-rata $\pm 2,5$ $3 \mathrm{Kg}$. Jenis gurita Octopus cyanea yang tertangkap di Perairan Kabaena Barat dapat dilihat pada Gambar 5.

Hasil wawancara dengan nelayan menyebutkan bahwa produksi gurita secara temporal pada musim barat lebih tinggi dibandingkan pada musim timur. Hasil tangkapan gurita berdasarkan musim dapat dilihat pada Tabel 2.

Hasil observasi berdasarkan fase bulan gelap terang menunjukkan bahwa gurita dominan ditemukan pada Fase Bulan III atau fase bulan terang menuju gelap. Berdasarkan nilai efektivitas sebesar $50 \%$ maka pada fase bulan III dapat dikategorikan sebagai waktu yang efektif untuk melakukan penangkapan gurita. Hasil tangkapan gurita berdasarkan fase bulan dapat dilihat pada Tabel 3.
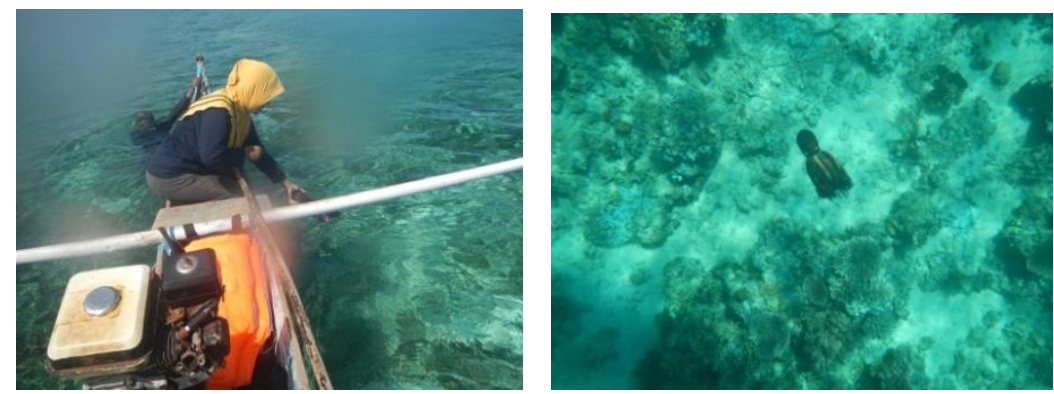

Gambar 3 Metode penangkapan alat tangkap pocong-pocong
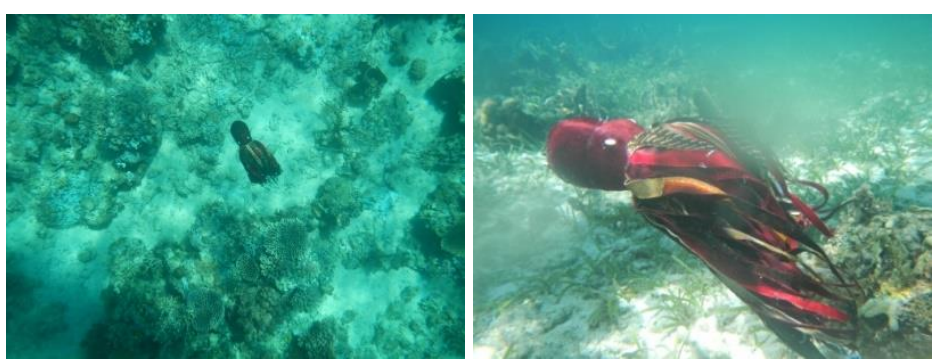

Gambar 4 Dasar perairan Kecamatan Kabaena Barat

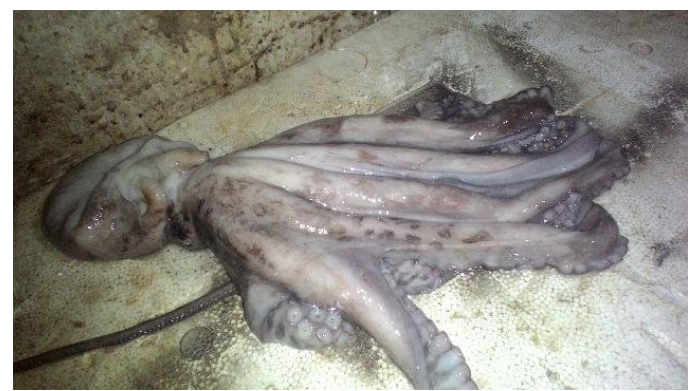

Gambar 5 Gurita jenis Octopus cyanea 
Tabel 2 Hasil tangkapan gurita berdasarkan musim penangkapan

\begin{tabular}{ccc}
\hline Tahun & \multicolumn{1}{c}{ Hasil Tangkapan Gurita $\mathbf{( K g )}$} \\
\hline 2010 & Musim Barat & Musim Timur \\
2011 & 50 & 10 \\
2012 & 500 & 50 \\
2013 & 50 & 20 \\
2014 & 600 & 60 \\
2015 & 30 & 5 \\
\hline Total & 400 & 40 \\
\hline Efektivitas & $\mathbf{1 . 6 3 0}$ & $\mathbf{1 8 5}$ \\
(\%) & $\mathbf{9 0}$ & $\mathbf{1 0}$ \\
\hline
\end{tabular}

Sumber : Kelompok nelayan gurita di Kabaena Barat

Tabel 3 Hasil tangkapan gurita berdasarkan fase bulan

\begin{tabular}{ccccc}
\hline \multirow{2}{*}{ Pengamatan } & \multicolumn{5}{c}{ Hasil Tangkapan Gurita (Kg) } \\
\cline { 2 - 5 } & Fase Bulan I & Fase Bulan II & Fase Bulan III & Fase Bulan IV \\
\hline 1. & 2 & 3 & 12 & 12 \\
2. & - & 1 & 12 & 18 \\
3. & 1 & 2 & 15 & 9 \\
4. & 2 & 2 & 13 & 8 \\
5. & 3 & 6 & 20 & 14 \\
6. & 3 & 3 & 16 & 5 \\
7. & 2 & 6 & 17 & $\mathbf{6 7}$ \\
\hline Total & $\mathbf{1 3}$ & $\mathbf{2 3}$ & $\mathbf{1 0 5}$ & $\mathbf{3 2}$ \\
\hline $\begin{array}{c}\text { Efektivitas } \\
\text { (\%) }\end{array}$ & $\mathbf{6}$ & $\mathbf{1 1}$ & $\mathbf{5 0}$ &
\end{tabular}

\section{PEMBAHASAN}

Karateristik suatu wilayah menjadi salah satu faktor yang mempengaruhi kebiasaan hidup dan mata pencarian dari kelompok masyarakatnya. Hal ini tergambar secara jelas bahwa Kecamatan Kabaena Barat yang terletak di wilayah pesisir, 58\% penduduk bermatapencarian sebagai nelayan. Nelayan yang terdapat di Kecamatan Kabaena Barat termasuk dalam kategori nelayan utama dan nelayan sambilan. Nelayan utama yaitu seseorang sumber penghasilan utamanya dan menghabiskan waktunya dengan melakukan kegiatan penangkapan ikan. Nelayan sambilan yaitu seseorang yang menjadikan kegiatan penangkapan ikan sebagai kegiatan sambilan. Nelayan sambilan yang terdapat di Kecamatan Kabaena Barat mayoritas bermata pencarian utama sebagai pegawai negeri sipil, berkebun dan wiraswasta lainnya.

Alat tangkap yang digunakan di Kecamatan Kabaena Barat beragam sesuai dengan sasaran ikan yang menjadi target tangkapan nelayan. Alat tangkap terdiri dari bagan, sero dan pancing pocong-pocong. Penggunaan pancing pocong-pocong oleh masyarakat di Kecamatan Kabaena Barat sangat dominan. Hal ini dike- tahui dari hasil observasi bahwa dari $58 \%$ jumlah nelayan yang ada di Kecamatan Kabaena Barat, $52 \%$ nelayan yang mengoperasikan alat tangkap pancing pocong-pocong. Tingginya jumlah pengguna pancing pocong-pocong disebabkan produk tangkapan yang dihasilkan berupa gurita yang memiliki nilai jual yang tinggi. Alasan lain dari penggunaan alat tangkap pcocng-pocong yaitu kontruski sederhana, teknologi pembuatannya tidak rumit dan murah.

Sumberdaya gurita yang terdapat di perairan Kecamatan Kabaena Barat menjadi salah satu produk unggulan di wilayah tersebut sebab dapat diperolah sepanjang waktu, walaupun pada musim-musim tertentu hasil tangkapan berkurang (musim panceklik). Hasil tangkapan gurita yang diperoleh dijual kepada pengumpul gurita yang terdapat di Kecamatan Kabaena Barat. Harga penjualan gurita di tingkat pengumpul berbeda-beda pada musim puncak dan musim panceklik. Pada musim puncak harga gurita rata-rata senilai $\mathrm{Rp}$. $10.000,00 / \mathrm{Kg}$ dan pada musim panceklik harga gurita rata-rata senilai Rp. 30.000,00/Kg. Harga penjualan gurita yang tidak pasti perlu mendapat perhatian dari pemerintah, sehingga tidak terjadi permainan harga pada tingkat pengumpul. 
Penelitian mengenai alat tangkap gurita telah dilakukan oleh beberapa peneliti. Safari et al. (2012) menjelaskan bahwa bubu merupakan salah satu alat tangkap gurita yang sangat ramah lingkungan. Penelitian alat tangkap gurita juga dilakukan oleh Moreno et al. (2008) dengan menggunakan alat tangkap pancing "Chilean long line". Deskripsi Chilean long line menyerupai alat pancing long line, namun pada tiap branch line diberikan jaring yang didesain menyerupai bubu berbentuk corong. Nurdiansyah et al. (2015) menjelaskan bahwa konstruksi alat tangkap pancing jigger yang dioperasikan untuk penangkapan gurita konstruksinya sangat sederhana. Satu unit alat tangkap hanya terdiri dari dua bagian, yaitu penggulung (reel) dan tali (line). Kontruksi yang berbeda pada pancing pocong-pocong yang terdiri dari mata pancing dan atraktor yang menyerupai pocong pada saat dioperasikan di perairan. Kontruksi atraktor pancing tersebut, sehingga alat tangkap ini dikenal dikalangan nelayan gurita di Sulawesi Tenggara sebagai pancing pocong-pocong.

Penelitian mengenai metode penangkapan gurita dengan memanfaatkan tingkah laku gurita menggunakan pancing dan umpan tiruan telah dilakukan oleh beberpa peneliti. Farikha et al. (2014), menjelaskan bahwa tingkah laku gurita (Octopus sp) terhadap umpan tiruan dalam bentuk kepiting dan udang memberikan perbedeaan yang signifikan. Umpan tiruan berbetuk kepiting memperoleh hasil tangkapan gurita yang lebih banyak dibandingkan umpan tiruan berbetuk udang. Selanjutnya Farikha et al. (2014), menjelaskan bahwa warna umpan tidak memberikan reaksi yang berpengaruh terhadap tingkah laku gurita. Metode penangkapan gurita menggunakan bubu memanfaatkan umpan cangkang keong yang sudah kosong untuk menarik perhatian gurita mendekati alat tangkap tersebut (Safari et al. 2012). Penangkapan gurita menggunakan alat tangkap pocong-pocong secara teknis terkait konstruksi dan metode penangkapannya belum pernah terpublikasi, sehingga penerbitan artikel ini dapat menjadi informasi awal bagi peneliti selanjutnya terkait penggunaan alat tangkap pcocong-pocong untuk penangkapan gurita.

Keberhasilan kegiatan penangkapan ikan ditentukan pula oleh kondisi perairan yang produktif untuk menjadi daerah penangkapan ikan yang potensial. Wilayah terumbu karang dengan transparansi peraian yang tinggi menjadi salah satu satu indikator kesuburan perairan dan kaya dengan biota perairan. Daerah penangkapan gurita di Kecamatan Kabaena Barat dominan dilakukan di perairan Kecamatan Kabaena Barat. Kondisi terumbu karang dan dasar berpasir menjadi gambaran dasar perairan di Kecamatan
Kabaena Barat. Bubun et al. (2015) menjelaskan bahwa biota perairan akan berada di suatu wilayah perairan disebabkan oleh dua faktor yaitu adanya interaksi fisik dan biologi terhadap lingkungannya. Paruntu et al. (2009) menjelaskan bahwa gurita jenis Octopus cyanea sebagai salah satu biota yang menempati perairan pada lapisan demersal mendiami wilayah pasir, batu, bekas cangkang moluska lainnya dan bendabenda lainnya yang berada pada dasar perairan pada kedalaman 25 meter dari permukaan laut. Martins et al. (2011) menjelaskan bahwa gurita merupakan penghuni laut dasar dan umumnya menempati daerah karang. Berdasarkan hasil penelitian dan pendapat dari peneliti tersebut, maka dapat dijelaskan bahwa interaksi fisik gurita terhadap lingkungan perairan di Kecamatan Kabaena Barat menjadi habitat yang cocok untuk gurita(Octopus cyanea), sebab dasar perairan terdiri dari pasir dan batu-batu karang menjadi rumah bagi gurita.

Interkasi biologi antara Octopus cyanea dengan lingkungannya diketahui dengan terdapatnya jenis-jenis kerang yang menjadi sumber makanan bagi gurita jenis ini. Quintana et al. (2008) menjelaskan bahwa jenis-jenis udang dan kerang-kerangan menjadi sumber makanan bagi beberapa spesies gurita. Boyle (1996), mengemukakan bahwa $O$. briareus memakan bermacam-macam binatang, tetapi makanan mereka terutama adalah udang dan ketam. Lobster, polychaeta dan berbagai jenis ikan juga dikonsumsi. Beberapa jenis gurita dikenal sebagai pemburu dengan berbaring dan menunggu di dalam sarangnya, tetapi jika mangsa belum datang juga di sekitarnya, maka akan mengejarnya.

Hasil penelitian efektivitas penangkapan gurita berdasarkan musim menunjukkan bahwa pada musim barat (Bulan Desember-Bulan Februari) produksi gurita di Kecamatan Kabaena Barat lebih tinggi dibandingkan pada musim timur (Bulan Juni-Bulan Agustus). Hal ini disebabkan pada musim barat perairan berada pada gelombang tinggi. Pada saat gelombang tinggi dapat menyebabkan terjadinya pengadukan perairan yang dapat menghasilkan sumber makanan bagi gurita. Hal ini dimanfaatkan oleh nelayan di pesisir Kecamatan Kabaena Barat untuk melakukan penangkapan gurita. Sebaliknya pada musim timur, kondisi perairan berada dalam keadaan teduh, sehingga sumber makanan bagi gurita relatif lebih rendah.

Hasil penelitian Sukresno dan Kasa (2008) menjelaskan bahwa suhu perairan di Laut Banda pada musim barat lebih hangat mencapai $30^{\circ} \mathrm{C}$ dibandingkan pada musim timur mencapai suhu $24^{\circ} \mathrm{C}$. Bubun et al. (2015) menjelaskan bahwa suhu permukaan laut di wilayah 
pesisir Laut Banda pada bulan Nopember-bulan Januari berkisar $27^{\circ} \mathrm{C}-30^{\circ} \mathrm{C}$ dengan salinas berkisar 33\%o-35\%o. Nontji (2007) menjelaskan bahwa salinitas perairan di Indonesia pada musim barat berkisar antara 33\%o-34\%. Samudera et al. (2016) menjelaskan bahwa habitat yang baik untuk kelangsungan hidup beberapa jenis Cephalopoda yaitu berada pada perairan dengan salinitas $30 \% 0-31 \%$ dan suhu $28^{\circ} \mathrm{C}$ $30^{\circ} \mathrm{C}$. Hasil penelitian menunjukkan bahwa di daerah penangkapan gurita Tanjung Melati memiliki suhu permukaan laut berkisar $27^{\circ} \mathrm{C}$ $28^{\circ} \mathrm{C}$ dan salinitas berkisar $35 \%$. Berdasarkan informasi dari beberapa penelitian dan hasil penelitian menunjukkan bahwa kondisi perairan Kecamatan Kabaena Barat merupakan daerah penangkapan gurita yang produktif pada musim barat (Desember- Februari).

Hasil analisis mengenai efektivitas waktu penangkapan gurita dapat ditentukan bahwa hasil tangkapan gurita menggunakan alat tangkap pocong-pocong memiliki tingkat efektivitas tertinggi sebesar $50 \%$ pada Fase Bulan III (Tabel 3). Hal ini berhubungan dengan kondisi pasang surut air laut berdasarkan fase bulan gelap terang. Produksi gurita secara temporal dipengaruhi oleh waktu penangkapan. Waktu penangkapan sumberdaya perikanan termasuk gurita secara umum terbagi dalam dua musim yaitu musim barat dan musim timur. Selain penangkapan gurita berdasarkan musim, penangkapan gurita juga dipengaruhi oleh fase bulan yang erat hubungannya dengan kondisi pasang surut air laut. Romimohtarto dan Juwana (2007) menjelaskan bahwa pergerakan pasang surut air laut akibat perubahan fase bulan dapat mempengaruhi penyebaran dan tingkah laku biota perairan. Penyebaran biota gurita di perairan dapat mempengaruhi produksi gurita.

Perubahan pasang surut air laut berhubungan langsung dengan perubahan pada tahapan fase bulan gelap terang. Tulungen et al. (2012) menjelaskan bahwa kecepatan arus pasang surut pada bulan purnama (fase bulan III) lebih rendah dibandingkan pada saat bulan awal (fase bulan I), perbani awal (fase bulan II) dan perbani akhir (fase bulan IV). Asuhadi dan Arafah (2016) menjelaskan bahwa penangkapan gurita di Desa Waha Wangi-wangi dilakukan biasanya pada saat air laut surut.

Hasil penelitian menunjukkan bahwa waktu penangkapan gurita yang efektif berdasarkan fase bulan yaitu pada fase bulan III (bulan purnama). Pada fase bulan III, air laut berada dalam kondisi pasang tinggi dan cahaya bulan lebih terang pada semua bagian permukaan air. Hasil penelitan Guntur et al. (2015) menjelaskan bahwa gurita merupakan salah satu spesies yang tertangkap pada alat tangkap bagan tancap sebanyak $0,25 \mathrm{Kg}$ pada intensitas cahaya 290 lux; $0,5 \mathrm{Kg}$ pada intensitas cahaya 2700 lux dan $0,75 \mathrm{Kg}$ pada intensitas cahaya 3900 lux. Hal ini menunjukkan bahwa secara fisik spesies gurita dapat berada lebih banyak disekitar perairan apabila intensitas cahaya yang diberikan lebih tinggi.

Dasar perairan Kecamatan Kabaena Barat yang terdiri dari ekosistem terumbu karang dan lamun menjadi daerah penangkapan yang produktif untuk spesies gurita. Pada saat pasang tinggi (fase bulan III/bulan purnama), wilayah ekosistem terumbu karang umumnya terendam air laut. Hal ini dimanfaatkan nelayan gurita untuk mengoperasikan alat tangkap pocong-pocong untuk memperoleh hasil tangkapan gurita yang dimulai pada pukul 06.00 WITA-12.00 WITA. Berdasarkan hal tersebut dapat dijelaskan bahwa waktu yang efektif mengoperasikan alat tangkap pocong-pocong untuk menangkap gurita di perairan Kecamatan Kabaena Barat Kecamatan Kabaena Barat dapat dilakukan pada musim barat, fase bulan III (bulan purnama) dan pukul 06.00 WITA-12.00 WITA. Pasang tinggi pada saat bulan purnama terjadi pada pukul 06.00. Kondisi ini dimanfaatkan oleh nelayan di wilayah perairan pantai untuk melakukan penangkapan ikan, sebab wilayah pantai menjadi daerah penangkapan ikan yang baik untuk beberapa spesies termasuk gurita.

\section{KESIMPULAN}

Berdasarkan hasil penelitian disimpulkan bahwa kontruksi alat tangkap pocong-pocong terdiri dari satu buah atraktor terbuat dari semen cor $(\mathrm{w}=5 \mathrm{~kg})$ yang dibungkus dengan kain berwarna merah, tali atraktor dari bahan nylon monofilamen $(\varnothing=2 \mathrm{~mm}, \mathrm{~L}=20 \mathrm{~m})$, delapan buah mata pancing nomor 10 yang melekat pada bagian pemberat $(0,5 \mathrm{~kg})$, dan tali pancing dari bahan nylon monofilamen $(\varnothing=2 \mathrm{~mm}, \mathrm{~L}=80 \mathrm{~cm})$.

Efektivitas penagkapan gurita secara temporal di Kecamatan Kabaena Barat berdasarkan fase bulan yaitu pada fase bulan III sebesar $50 \%$ lebih banyak daripada fase bulan lainnya. Berdasarkan musim yaitu pada musim barat sebesar $90 \%$ lebih banyak dibandingkan pada musim timur. Berdasarkan waktu penangkapan dapat dilakukan pada siang hari pada pukul 06.00 WITA - 12.00 WITA.

\section{SARAN}

Penelitian terkait teknologi penangkapan gurita dengan menggunakan pocong-pocong masih perlu dilakukan beberapa kajian. Hal ini 
terkait tingkat keramahan lingkungan alat tangkap, efektivitas jumlah mata pancing yang digunakan dan pengaruh perbedaan warna kain atraktor terhadap hasil tangkapan gurita.

\section{UCAPAN TERIMA KASIH}

Penulis mengucapkan terima kasih kepada: 1) Kementrian Riset dan Teknologi Pendidikan Tinggi atas pendanaan dalam Hibah Penelitian pada skim Penelitian Dosen Pemula; 2) Lembaga Penelitian dan Pengabdian Masyarakat Universitas Muhammadiyah Kendari sebagai fasilitator dalam kegiatan penelitian; 3) Kepala Kecamatan Kabaena Barat dan Kepala Desa Sikeli sebagai fasilitator dalam pelaksanaan penelitian terkait pengumpulan data sekunder nelayan gurita; 4) Ikatan Alumni Fakultas Perikanan dan IImu Kelautan Kecamatan Kabaena Barat, sebagai fasilitator lapangan dalam kegiatan penelitian; 5) Jurnal Marine Fisheries sebagai wadah penerbitan Jurnal Nasional Terakreditasi.

\section{DAFTAR PUSTAKA}

Asuhadi S, Arafah N. 2016. Kearifan Lokal Masyarakat Wangi-Wangi dalam Pemanfaatan Zona Pasang Surut secara Berkelanjutan. Ecogreen. 2(2): 79 - 88.

Baskoro M, Telussa RF, Purwangka F. 2006. Efektivitas bagan Motor di Perairan Waai, Pulau Ambon: Prosiding Seminar Perikanan Tangkap. ISBN : 976 - 1225 - 001. Departemen Pemanfaatan Sumberdaya Perikanan. Bogor: Institut Pertanian Bogor.

Boyle P.R. 1996. Cephalopod populations : Definition and dynamics. Published 29 August 1996 doi:10.10.1098/rstb.1996 .0089 Phil.Trans.R.Soc.Lond. 351(1343): 985-1002.

Bubun RL, Simbolon D, Nurani TW. Wisudo SH. 2015. Terbentuknya Daerah Penangkapan Ikan dengan Light Fishing. Journal Airaha. 4(1): 27-36.

Farikha K, Pramonowibowo, Asriyanto. 2014. The influence of difference shape and colour artificial bait againts the catch of octopus at hand line in Baron Water Area, Gunung Kidul. Journal of Fisheries Resources Utilization Management and Technology. 3(3): 275-283.

Guntur, Fuad, Muntaha A. 2015. Pengaruh Intensitas Lampu Nawah Air terhadap Hasil Tangkapan Pada Alat Tangkap Bagan
Tancap. Mariene Fisheries. 6(2): 195202.

Kantor Kecamatan Kabaena Barat. 2015. Data Penduduk Berdasarkan Matapencaharian. Kecamatan Kabaena Barat.

Martins VS, Schiavetti A, Souto FJB. 2011. Ethnoecological knowledge of the artisan fishermen of octopi (Octopus spp.) in the community of Coroa Vermelha (Santa Cruz Cabrália, Bahia). Annals of the Brazilian Academy of Sciences. 83(2): 513-522.

Moreno CA, Castro R, Mujica LJ, Reyes P. 2008. Significant conservation benefits obtained from the use of a new fishing gear in the Chilean Patagonian Toothfish Fishery. CCAMLR Science. 5:79-91.

Nontji. 2007. Laut Nusantara. Jakarta: Djamba$\tan$

Nurdiansyah L, Pramonowibowo, Fitri ADP. 2015. Analisis Perbedaan Jenis Umpan Terhadap Hasil Tangkapan Pada Pancing Gurita (Jigger) Di Perairan Karimunjawa, Jawa Tengah. Journal of Fisheries Resources Utilization Management and Technology. 4(4): 157-163.

Paruntu CP, Boneka FB, Talare SL. 2009. Gurita (Cephalopoda) dari Perairan Sangihe, Sulawesi Utara. EKOTON. 9(2): 13-27.

Quintana D, Domingues P, Garcia S. 2008. Effect of Two Artificial Wet Diets Agglutinated with Gelatin on Feed and Growth Performance of Common Octopus (Octopus Vulgaris) Sub-Adults. Aquaculture. 280(2008): 161-164.

Romimohtarto K, Juwana S. 2007. Biologi Laut Ilmu Pengetahuan tentang Biota Laut. 2007. Jakarta: Djambatan

Safari H, Rengi P, Brown A. 2012. Fishing technology studies at octopus bubu Nagalawan Sei Serdang District Perbaungan Bedagai North Sumatra Province. Fakultas Perikanan dan IImu Kelautan. Pekanbaru: Universitas Riau.

Samudera NR, Hartoko A, Sulardiono B. 2016. Hubungan Salinitas terhadap Perkembangan Telur Cephalopoda yang Didapat pada Perairan Pantai Bondo Kabupaten Jepara. Management of Aquatic Resources. 5(2): 70-79.

Simbolon D, Jeujanan B, Wiyono ES. 2011. Efektivitas Pemanfaatan Rumpon Pada Operasi Penangkapan Ikan di Perairan 
Kei Kecil, Maluku Tenggara. Marine Fisheries. 2(1): 19-28.

Sukresno B, Kasa IW. 2008. Dynamical Analysis of Banda Sea Concerning with El Nino, Indonesian Through Flow and Monsoon by Using Satellite Data and Numerical Model. Ecotrophic. 3 (2): 8791.

Tulungen D, Kalangi PNI, Patty W. 2012. Kajian Pola Arus di Daerah Penangkapan Bagan Apung di Desa Tateli Weru. Jurnal Ilmu dan Teknologi Perikanan Tangkap. 1(2): 27-32.

Yuliani W, Ali MS, Saputri M. 2016. Pengelolaan Ekosistem Terumbu Karang Oleh Masyarakat di Kawasan Lhokseudu Kecamatan Leupung Kabupaten Aceh Besar. Jurnal Ilmiah Mahasiswa Pendidikan Biologi. 1(1): 1-9.

Zulkarnain, Baskoro MS, Martasuganda S, Monintja D. 2011. Pengembangan Desain Bubu Lobster yang Efektif. Buletin PSP. 19(2): 45-57. 